\title{
Gonadotropin-releasing hormone agonist-induced pituitary apoplexy
}

\author{
Fergus Keane', Aoife M Egan1,3, Patrick Navin², Francesca Brett ${ }^{4}$ and \\ Michael C Dennedy 1,3
}

'Department of Endocrinology, 2Department of Radiology, University Hospital Galway, Newcastle, Galway, Ireland, ${ }^{3}$ School of Medicine, National University of Ireland Galway, Newcastle, Galway, Ireland and 4Department of Pathology, Beaumont Hospital, Beaumont Road, Dublin 9, Ireland

Correspondence should be addressed to A Egan

Email

aoife.egan@gmail.com

\section{Summary}

Pituitary apoplexy represents an uncommon endocrine emergency with potentially life-threatening consequences. Drug-induced pituitary apoplexy is a rare but important consideration when evaluating patients with this presentation. We describe an unusual case of a patient with a known pituitary macroadenoma presenting with acute-onset third nerve palsy and headache secondary to tumour enlargement and apoplexy. This followed gonadotropin-releasing hormone (GNRH) agonist therapy used to treat metastatic prostate carcinoma. Following acute management, the patient underwent transphenoidal debulking of his pituitary gland with resolution of his third nerve palsy. Subsequent retrospective data interpretation revealed that this had been a secretory gonadotropinoma and GNRH agonist therapy resulted in raised gonadotropins and testosterone. Hence, further management of his prostate carcinoma required GNRH antagonist therapy and external beam radiotherapy. This case demonstrates an uncommon complication of GNRH agonist therapy in the setting of a pituitary macroadenoma. It also highlights the importance of careful, serial data interpretation in patients with pituitary adenomas. Finally, this case presents a unique insight into the challenges of managing a hormonal-dependent prostate cancer in a patient with a secretory pituitary tumour.

\section{Learning points:}

- While non-functioning gonadotropinomas represent the most common form of pituitary macroadenoma, functioning gonadotropinomas are exceedingly rare.

- Acute tumour enlargement, with potential pituitary apoplexy, is a rare but important adverse effect arising from GNRH agonist therapy in the presence of both functioning and non-functioning pituitary gonadotropinomas.

- GNRH antagonist therapy represents an alternative treatment option for patients with hormonal therapy-requiring prostate cancer, who also have diagnosed with a pituitary gonadotropinoma.

\section{Background}

Pituitary apoplexy represents one of the most serious, lifethreatening endocrine emergencies requiring immediate management. It is a clinical syndrome associated with sudden headache, vomiting, visual impairment and meningismus caused by the rapid enlargement of a pituitary adenoma usually due to infarction of the tumour (1). In pituitary adenomas, the normal pattern of blood supply from the hypothalamo-hypophyseal portal system is altered, with evidence of neovascularization from alternative sources and changes in histological characteristics of the capillaries. These changes may contribute to an increased risk of ischemia and bleeding (2). 
Usually, apoplexy occurs in patients without a known diagnosis of a pituitary adenoma but may also occur in patients who have known functioning or non-functioning tumour (1). Recent data suggest that pituitary adenomas occur in almost $20 \%$ of the general population. The majority of these are non-functioning gonadotropinomas (3). Clinically functioning gonadotropinomas, however, are very rare and in males tend to be universally associated with elevated follicular-stimulating hormone (FSH) with varying levels of luteinizing hormone (LH) and testosterone. Testicular enlargement may or may not be present and this may be due to the slow process of development of the sign or variable biological activity of the FSH on Sertoli cells within the testes (4). Gonadotrophinreleasing hormone (GNRH) has the potential to stimulate acute growth of pituitary gonadotropinomas, with 15 prior cases of pituitary apoplexy described in patients with both functioning and non-functioning gonadotropinomas $(2,5)$.

\section{Case presentation}

A 67-year-old man was presented to the emergency department complaining of headache ongoing for $24 \mathrm{~h}$. He also reported ptosis of the right eye that occurred acutely $6 \mathrm{~h}$ in advance of presentation. His ptosis was causing particular distress, and due to a previous mechanical injury to his left eye, it was rendering him severely visually impaired.

His past medical history was notable for a pituitary macroadenoma with no anterior pituitary hormone deficits and no encroachment on the optic chiasm. The tumour had been monitored over the previous 10 years and was found to be stable in size. As there was no evidence of tumour progression and the patient was asymptomatic, the tumour was managed conservatively. On retrospective review of the patient's biochemical results (Table 1), it is evident that this tumour was actually a functioning gonadotropinoma, but this had been overlooked. More recently, the patient had been diagnosed with prostate carcinoma (Gleason score 8 involving extracapsular extension) and had been treated with the GNRH agonist triptorelin 2 weeks before presentation.

Clinical examination on presentation revealed haemodynamic stability (blood pressure 132/80 mmHg, heart rate 89 beats per minute) and a right-sided third nerve palsy. Examination of the left eye confirmed a longstanding upper and lower outer quadrant visual field defect. The prostate gland was enlarged and irregular and there was no evidence of testicular enlargement. The remainder of the clinical examination was unremarkable.

\section{Investigation}

Table 1 illustrates the markedly elevated gonadotropin levels noted on presentation. The patient's biochemical findings 12 months before the presentation are also displayed, and suggest the presence of a secretory gonadotropinoma.

Magnetic resonance imaging (MRI) of the brain completed 3 months before presentation (Fig. 1A) revealed a $3.0 \times 3.0 \mathrm{~cm}$ mass arising from within the pituitary gland extending into the suprasellar cistern. There was no evidence of impingement on the optic chiasm and the overall appearances were consistent with prior MRI examinations. MRI on presentation (Fig. 1B) demonstrates interval tumour enlargement with the mass now measuring $3.5 \times 3.3 \mathrm{~cm}$. There is invasion into the cavernous sinus on the right with new ill-defined peripheral enhancement and poorly enhancing central component. This is consistent with pituitary infarction.

A working diagnosis of GNRH-induced pituitary apoplexy, with consequent third nerve palsy in a secretory gonadotropinoma was made.

\section{Treatment}

The patient was managed acutely with intravenous fluids and stress dose steroids (hydrocortisone $50 \mathrm{mg}$ three times daily intravenously). In consultation with

Table 1 Biochemical findings.

\begin{tabular}{|c|c|c|c|}
\hline & FSH (IU/L) & LH (IU/L) & Total testosterone $(\mathrm{nmol} / \mathrm{L})$ \\
\hline Normal range & $1.5-12.4$ & $1.7-8.6$ & $9.9-27.8$ \\
\hline 12 months before presentation & 52.4 & 3.8 & 13.6 \\
\hline On presentation & $>200$ & 50.0 & 27.1 \\
\hline 1 week post-operatively & 66.9 & 7.6 & 15.2 \\
\hline 12 months post-operatively & 5.7 & $<0.5$ & $<0.4$ \\
\hline
\end{tabular}




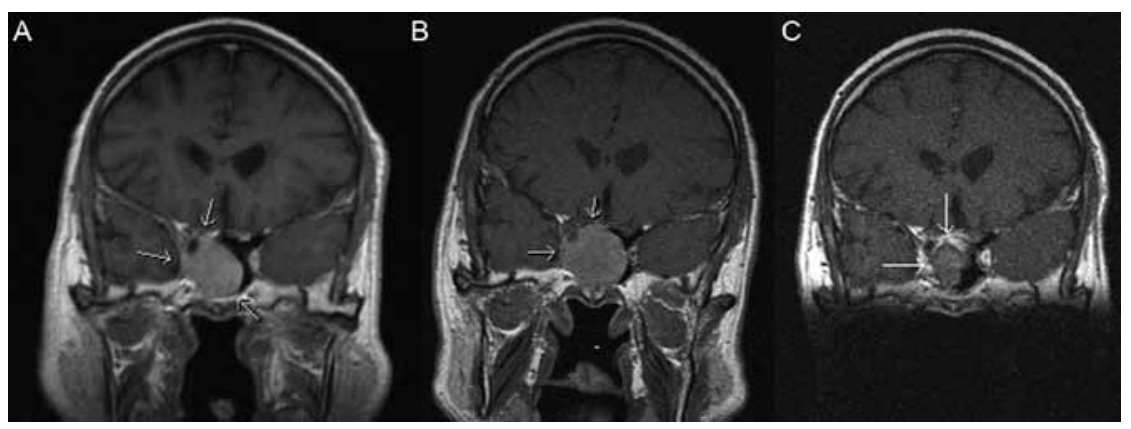

\section{Figure 1}

Delayed, dynamic contrast-enhanced, T1 weighted coronal images through the pituitary fossa, 3 months before (A) and at presentation (B). This reveals interval increase in the sellar mass (arrows) with new, ill-defined peripheral enhancement consistent with pituitary infarction. (C) demonstrates residual pituitary tissue $(1.0 \times 2.1 \mathrm{~cm}) 3$ months post transphenoidal debulking of the adenoma.

the neurosurgical team, it was decided that on the basis of severe visual compromise, debulking of the pituitary adenoma by endoscopic transphenoidal hypophysectomy was indicated. This was undertaken on day 3 following presentation. Histological examination revealed a partially infarcted pituitary adenoma expressing follicular stimulating hormone (FSH) and luteinizing hormone (LH). Figure $1 \mathrm{C}$ demonstrates residual pituitary tissue $(1.0 \times 2.1 \mathrm{~cm}) 3$ months post transphenoidal debulking of the adenoma.

\section{Outcome and follow-up}

The patient recovered well after pituitary surgery and was transitioned to oral hydrocortisone $5 \mathrm{mg}$ twice daily. He had a complete resolution of the third nerve palsy and no further headaches. Six months following discharge an adrenocorticotropic hormone (ACTH) stimulation test demonstrated normal adrenal function with baseline cortisol $265 \mathrm{nmol} / \mathrm{L}$ and $30 \mathrm{~min}$ post ACTH cortisol $787 \mathrm{nmol} / \mathrm{L}$. On this basis, empiric steroid replacement was stopped.

GNRH antagonist therapy (degarelix) was commenced to treat his prostate cancer and he also received local external beam radiotherapy to the prostate (74 Grey in 37 fractions). As outlined in Table 1 , this successfully reduced gonadotropin and testosterone concentrations. His prostate-specific antigen (PSA) levels were undetectable 12 months after indicating effective treatment.

\section{Discussion}

This rare case demonstrates the effects of GNRH agonist occurred with associated pituitary apoplexy and cranial nerve palsy. Two important points are highlighted in this case. First, it is important to regularly revisit formerly administration in a patient with a secretory gonadotropinoma. Acute tumour growth established diagnoses in relation to patients attending a long-term clinic. With a significantly elevated FSH at baseline, this gentleman had evidence of a functioning gonadotropinoma, but it was overlooked on multiple assessments. Secondly, it is of significant importance for the multidiscipline to address new-onset comorbidities in the context of already established diagnoses, and to use their combined expertise in order to tailor appropriate management plans for the individual patient.

The presentation of pituitary apoplexy overlaps with other important diagnoses, many of which are lifethreatening, thus prompt investigation is essential. MRI remains the imaging modality of choice in suspected cases. Consensus regarding the appropriate management of pituitary apoplexy has not been reached, owing to the rarity of the condition, the variety of aetiologies and the variable overall course of the condition. It is generally agreed that while many patients with pituitary apoplexy require surgical intervention, in particular those with neuro-ophthalmic deficit; selected patients may be managed conservatively and there are no randomized controlled data to demonstrate the benefit of either approach (6). As robust guidelines are not available, clinical decisions in this regard are still made on a caseby-case basis. Both medical and surgical approaches were successfully taken to manage previously reported cases of GNRH agonist-induced pituitary apoplexy $(2,7,8,9)$.

Gonadotrophin receptor hormone (GNRH) agonists are an important therapy for advanced stage prostate carcinoma. GNRH agonists typically cause an initial elevation in LH, FSH and testosterone, which become suppressed over time due to downregulation and de-sensitization of GNRH receptors in the pituitary gland (10). Consequent hypogonadism reduces testosterone, preventing or slowing prostate cancer cell proliferation. In the described case, due to the concurrent diagnosis of a pituitary gonadotropinoma, the initial gonadoptropin elevation was followed by tumour growth and apoplexy. Prior reports highlight that this phenomenon is not limited to functioning gonadotropinomas but has 
also occurred in non-functioning gonadotropinomas $(2,7,8,9)$.

While high-dose GNRH agonist therapy produces its effect by downregulating gonadotrophin receptors on the pituitary, GNRH antagonist therapy directly inhibits these receptors and represents an alternative for patients requiring androgen deprivation therapy (10). These antagonists produce an immediate and sustained suppression in FSH, LH, and testosterone that does not rely on the pharmacodynamic interactions within the individual. The decision to use GNRH antagonist therapy was taken on the basis of persistently raised LH, FSH and testosterone post-operatively. The positive therapeutic effect of this is interesting and demonstrates a pharmacological response to GNRH antagonists within a pituitary gonadotrophinoma. An interesting hypothesis arising from these findings is the possibility that these agents could be used to prevent growth or re-growth of pituitary adenomas which are likely to be gonadotrophinomas and which may demonstrate GNRH receptor expression. However, previous trials of such therapy have yielded inconsistent results.

\section{Declaration of interest}

The authors declare that there is no conflict of interest that could be perceived as prejudicing the impartiality of the research reported.

\section{Funding}

This research did not receive any specific grant from any funding agency in the public, commercial or not-for-profit sector.

\section{Patient consent}

Informed consent has been obtained from the patient for publication of the submitted article and accompanying images.
Author contribution statement

F K and A M E drafted the manuscript. P N selected the radiological images and contributed to manuscript drafting. M C D supervised the project and revised the manuscript drafts.

\section{Acknowledgements}

The authors would like to acknowledge our neurology, biochemistry and endocrinology colleagues in University Hospital Galway and our colleagues in endocrinology, neurosurgery and pathology in Beaumont Hospital Dublin who assisted in the management of this case.

\section{References}

1 Randeva HS, Schoebel J, Byrne J, Esiri M, Adams CBT \& Wass JAH 1999 Classical pituitary apoplexy: clinical features, management and outcome. Clinical Endocrinology 51 181-188. (doi:10.1046/j.13652265.1999.00754.x)

2 Guerra Y, Lacuesta E, Marquez F, Raksin PB, Utset M \& Fogelfeld L 2010 Apoplexy in non functioning pituitary adenoma after one dose of leuprolide as treatment for prostate cancer. Pituitary 13 54-59. (doi:10.1007/s11102-009-0202-2)

3 Mete O \& Asa SL 2012 Clinicopathological correlations in pituitary adenomas. Brain Pathology 22 443-453. (doi:10.1111/bpa.2012.22.issue-4)

4 Ntali G, Capatina C, Grossman A \& Karavitaki N 2014 Functioning gonadotroph adenomas. Journal of Clinical Endocrinology \& Metabolism 99 4423-4433.

5 Sasagawa Y, Tachibana O, Nakagawa A, Koya D \& Iizuka H 2015 Pituitary apoplexy following gonadotropin-releasing hormone agonist administration with secreting pituitary adenoma. Journal of Clinical Neuroscience 3 601-603. (doi:10.1016/j.jocn.2014.08.015)

6 Chanson P, Lepeintre J \& Ducreux D 2004 Management of pituitary apoplexy. Expert Opinion on Pharmacotherapy 5 1287-1298. (doi:10.1517/14656566.5.6.1287)

7 Morsi A, Jamal S \& Silverberg JD 1996 Pituitary apoplexy after leuprolide administration for carcinoma of the prostate. Clinical Endocrinology 44 121-124. (doi:10.1046/j.1365-2265.1996.644465.x)

8 Ando S, Hoshino T \& Mihara S 1995 Pituitary apoplexy after goserelin. Lancet 345 458. (doi:10.1016/S0140-6736(95)90443-3)

9 Hanson P \& Schaison G 1995 Pituitary apoplexy caused by GnRHagonist treatment revealing gonadotroph adenoma. Journal of Clinical Endocrinology \& Metabolism 80 2267-2268.

10 Eckstein N \& Haas B 2014 Clinical pharmacology and regulatory consequenes of GnRH analogues in prostate cancer. European Journal of Clinical Pharmacology 70 791-798. (doi:10.1007/s00228-014-1682-1)

Received in final form 25 April 2016

Accepted 10 May 2016 